OBITUARY

\title{
In memory of Dr. S. K. Noordeen. 1933-2021
}

\author{
P. Narasimha Rao ${ }^{\mathrm{a}} \&$ M. D. Gupte ${ }^{\mathrm{b}}$ \\ ${ }^{a}$ Bhaskar Medical College, Dermatology, Telangana, India \\ ${ }^{\mathrm{b}}$ National Institute of Epidemiology, India
}

Submitted and accepted 17 November 2021

Dr. Shaik Khader Noordeen was a visionary who worked vigorously to translate the concept of global leprosy control into a successful programme in all the countries endemic for leprosy. Noordeen was born in Keeranur, Tamilnadu, India and had his early medical education in Chennai, followed by postgraduate education in public health in Calcutta, India and Michigan, USA. Based on his strong interest in leprosy, he joined the Central Leprosy Teaching \& Research Institute (CLTRI), Chingleputtu, India, in the year 1958 and served there for more than two decades where he initiated research in epidemiology, clinical leprosy, prevention, and rehabilitation. He was closely associated with Dr. H. Srinivasan, Dr. M. Christian, Dr. P. Neelan and Dr. D. G. S. Iyer, among others during this period.

Early in his career, joining hands with Dr. H. Srinivasan, he carried out studies in pure neural leprosy (PNL) which remain a benchmark for epidemiological data on this unique form of leprosy. His work on dapsone prophylaxis in leprosy is a monumental contribution in leprosy epidemiology. He was particularly encouraging towards young medical graduates and postgraduate students to motivate them to take up a career in leprosy. Many of us have personal recollections of time spent in thought-provoking interactions with him.

Based on his unique contribution in India, the WHO invited him in 1979 to join its Leprosy Programme in Geneva where he served as Medical Officer, Chief Medical Officer, and ultimately as Director of the Global Programme for the Elimination of Leprosy. It is in this capacity that Noordeen is widely recognized as the chief architect behind the WHO's successful global effort to eliminate leprosy as a public health problem. During his stint at WHO for nearly 20 years he was responsible for the promotion of leprosy control and the implementation of Multi Drug Therapy (MDT). He took a key role in developing the concept of Leprosy Elimination and was instrumental for the World Health Assembly resolution on 'Elimination of Leprosy as a Public Health Problem by year 2000' in 1991. The South India BCG leprosy prevention trial, Multi-arm Leprosy Vaccine Trial and WHO chemotherapy studies done in India and other leprosy endemic countries had his imprint.

Noordeen provided leadership to the leprosy world as the President of Indian Association of Leprologists (2000-2002) and of the International Leprosy Association (2002-2008). He also served as editor of the prestigious Indian Journal of Leprosy from 2000 to 2010.

Correspondence to: P. Narasimha Rao (e-mail: dermarao@gmail.com) 
He received several international and national awards and recognitions, the most important were, the International Gandhi Award and Padma Sri.

Noordeen is survived by his wife Mrs Fathima Noordeen and sons Dr. Mohideen, Mr. Nazeemudeen and daughter Ms. Sarah Noordeen-Monnier. Through his work he has left an indelible mark in the field of Indian and global leprosy. We offer our sincere condolences to the family on his passing away. 